\title{
Cursos e Programas de Ensino em Turismo - Realidade de Cinco Cidades Brasileiras
}

\author{
Doris Van de Meene Ruschmann \\ Mirian Rejowski ${ }^{2}$
}

Maria Cristina Cacciamali

RESUMO: Este artigo sintetiza inicialmente os estudos sobre a capacitação de recursos humanos para o Turismo no mundo e na América Latina. Em seguida, apresenta informações sobre o ensino em Turismo e Hotelaria no Brasil e destaca os principais resultados de pesquisa aplicada a entidades de ensino de Manaus, Salvador, Rio de Janeiro, São Paulo e Florianópolis. Descreve e analisa esses resultados em relação a cursos regulares e cursos não-regulares. Aponta recomendações para a valorização e melhoria da formação e capacitação de recursos humanos para o Turismo no Brasil.

PALAVRAS-CHAVE: Ensino em Turismo; entidades cursos e programas; Manaus, Salvador, Rio de Janeiro, São Paulo e Florianópolis; Brasil.

ABSTRACT: This article presents the Tourism human resources capacitation studies on the world and on the Latin America. It presents data about Brazil Tourism Education and it emphazises the main research results applied in five Brazilian cities: Manaus, Salvador, Rio de Janeiro, São Paulo and Florianópolis. It describes and analysis these results in relation of the regular and

Bacharel em Turismo. Mestre e Doutora em Ciências da Comunicąãa (Turismo) pela ECA-USP. Docente dos cursos de graduacão e pós-graduação da ECA.USP e do SENAC-SP. Consultora em Planejamento e Marketing Turistico

2. Bacharel em Turismo Agua da ECA USP

de graduação e pós-graduação da ECA-USP. Delegada Adjunta da AMFORT no Brasil. Editora da revista "Turismo em Análise". Fax: (011) 818-4331.

Bacharel em Economia. Mestre e Doutora em Teoria Econômica pela FEA.USP. Livre-Docente em Desenvolvimento Econômico e em Economia do Trabalho pela FEA.USP. Professora Titular do Departamento de Ensino de Economia de programas de graduação e de pós-graduação. e-mail. cacciama@usp.br. 
irregular courses. It points the recommendations, for the valorization and advance of the human resources capacitation and formation for the Brazil Tourism.

KEY WORDS: Tourism education; institutions; courses and programs; Manaus, Salvador, Rio de Janeiro, Sĩo Paulo and Florianópolis; Brazil.

\section{Introduçāo}

Esta pesquisa enfoca o ensino em Turismo, especificamente em cinco cidades brasileiras: Manaus (AM), Salvador (BA), Rio de Janeiro (RJ), São Paulo (SP) e Florianópolis (SC). A idéia de pesquisar tal tema surgiu em face da falta de informações sobre as entidades de ensino na área, a fim de:

- identificar e analisar as ofertas de cursos e programas voltados à formação, treinamento e reciclagem de profissionais do setor;

- oferecer subsidios para a formulação de uma politica de formação e aperfeiçoamento de recursos humanos para o Turismo.

Este estudo foi desenvolvido no período de janeiro a setembro de 1995, e faz parte da pesquisa da intitulada Condições e Perspectivas do Mercado de trabalho no Setor de Turismo. ${ }^{4}$

Inicialmente, com base em levantamento e análise bibliográfica de publicações e documentos técnicos sobre o tema, descreve-se a sintese dos estudos sobre a Capacitação de Recursos Humanos para o Turismo no mundo e na América Latina. Em seguida, expõe-se o diagnósticodo Ensino em Turismo no Brasil. A partir disso, apresentam-se os principais resultados da pesquisa de campo aplicada nas cidades já mencionadas, enfocando cursos regulares versus cursos não regulares.

No final, apontam-se recomendações para a valorização c melhoria d' formação e capacitação de recursos humanos no setor de Turismo no Brasil.

\section{Capacitaçāo de Recursos Humanos para o Turismo}

A capacitação de recursos humanos para o turismo depende da integração dos aspectos teóricos e práticos da atividade e se caracteriza pela diversidade dos

\footnotetext{
4. Pesquisa coordenada pelo prof: dr. Wilson Abrahão Rabahy, a pedido do Instituto Brasileiro de Turismo - Embratur, para
} a Secretaria de Formą̧ão de Desenvolvimento Protissional do Ministério do Trabalho elementos que interagem em diversos niveis: o setor publico, as empresas privadas, asinstituicões de ensino, os profissionais da área e o consumidor-turista. Apesar da as instituiçóes de ensidade premente de recursos humanos qualificados para atuar na área, a avaliação da intensidade, profundidade ou especificidade dessa formação passou a ser estudada e discutida de modo sistemático somente a partir da década de 80 . Fazse, a seguir, uma síntese de estudos sobre cssa temática no Exterior e no Brasil.

No início dos anos 80, Jafari (1981) organizou a edição especial da publicação Annals of Tourism Research, nos Estados Unidos, com a participação especial de Brent Ritchie, da Universidade de Calgary (Canadá), sobre o tema especifico "Educação em Turismo e sua Viabilidade", da qua

de dez autores, que realçaram a integração das dive

Turismo e a necessidade da visão global dos profiss

Em 1989, na Argentina, realizou-se o I Seminário Preparatorı do Congresso Internacional da Associación para la Formación Profesional Turistica - Amfort, sobre o tema "Capacitação Turística - Seu Rclacionamento junto as Setores Público ePrivado", que, alćm de pesquisadores da América Latina, contou com a participação de representantes dos Estados Unidos c da Eur

discutidos no evento, destacaram-se aqueles que enfatizavam a estruturaçao curricular dos institutos técnicos e superiores, as perspectivas latino-americanas para o setor c a formação superior em países desenvolvidos (Capacitación..., r)89).

Em 1990, realizou-se cm São Paulo o II Seminário da Amfort, que tratou do assunto "Turismo: Grande Desafio dos Anos 90". Desse Seminário, destacamse as seguintes condições:

- a necessidade da especialização dos recursos humanos e a maior capacitação profissional em todos os níveis e setores do sistema de Turismo

- maior capacitação dos docentes e gestores das áreas de formação e decisão nos setores público c privado, frente às inovações tecnológicas;

- incentivo ao conhecimento técnico-científico do turismo, através de estudos e pesquisas;

- necessidade de cstabelecimento de um modelo pedagógico comum à formação e à capacitação profissional em Turismo, para todos os países da América Latina;

- necessidade de estudos e programas de pesquisa e de atualização de novos métodos e técnicas de formação e capacitação profissional;

- integração entre centros de formação técnica e universitária em Turismo, empresas do setor e órgãos públicos responsáveis pelo planejamento e desenvolvimento turístico;

- permanente debate c intercâmbio de informações sobre planos de estudo 
metodologia do cnsino, com o objetivo de adoção do modelo pedagógico compatível com as características politicas e socioeconômicas dos países da Américi Latina (Turismo..., 1991).

Ainda cm 199(), a Association Internationale d'Experts Scientifiques du Tourism - AIEST, com sede em St. Gallen - Suiça, abordou o tcma "Formação Superior cm Turismo - Suas Necessidades c Exigências", cm seu 4(1) Congresso Anual, realizado em Berlim.

Os pesquisadores de todo o mundo reunidos nesse evento ressaltaram que a formação e aperfeiçoamento acadêmicos se distinguem da formação profissionalizante, principalmente na relação existente entrc o ensino c a pesquisa. Como recomendações e conclusões desse Congresso, destacou-se que:

- a educação superior em Turismo exige uma integração com as atividades práticas do setor;

- no futuro, a educação continuada tcrá significado crescente, tanto nas instituições de cnsino como nas cmpresas (on-the-job-training);

- a crescente intcrnacionalização dos cstudos de nível superior $\mathrm{cm}$ turismo constitui uma tendência que se consolida (AIEST, 199())

Em 1993, a situação da capacitação dos recursos humanos para o Turismo foi amplamente debatida c estruturada cm vários enfoques, durantc o I Simpósio Latino-Americano de Docentes c Pesquisadores Científicos do Turismo, realizado em Salvador (Brasil), no qual os especialistas discutiram a situação do setor na América Latina. Dentre os temas abordados nos diversos grupos de traballos, enfatizou-se o "Ensino do Turismo", sob a ótica de instituições de ensino e pesquisa em Turismo da Argentina, Unuguai, Venezuela, Mćxico, Cuba c de dez Estados brasileiros.

Considerando-se as particularidades e semelhanças das regiões da América Latina e o contexto no qual ela se insere na nova ordem mundial, tanto sociocconômica como aquela referente aos fluxos turísticos internacionais c ao turismo domćstico das nações, conclui-se que é preciso:

- desenvolver um projeto pedagógico permanente, voltado para a utilização de novas práticas de ensino para a formação profissional em Turismo c para al conseqüente absorção dos graduados pelo mercado de trabalho;

- realizar uma análise qualitativa das estruturas curriculares e dos programas clos diversos cursos superiores de Turismo, considerando a interdisciplinaridade;

- estruturar uma proposta metodológica fundamentada em projetos integrados baseados no conhecimento do contexto da formação dos recursos humanos para o Turismo, na sua adequação ao mercado de trabalho e nas tendências para o selor;

- buscar a atualização e a modernização das técnicas de ensino e das diferentes correntes de pensamento nas disciplinas da área de concentração;

- enfatizar a necessária visão holística na docência cm Turismo, uma vez que a dinâmica da atividade $\mathrm{c}$ a complexidade do fato $\mathrm{c}$ do fenômeno turístico exigem adequação c revisão permanentes dos modelos, que devem ser adaptados às realidades locais c às suas características ambientais, culturais, socioeconômicas e políticas (I Simpósio..., 1993).

Em outubro de 1994, realizou-sc, cm Montreal (Canadá), o IV Congresso Pan-Americano de Escolas de Hotelaria c Turismo c, nos debates realizados entre mais de quatrocentos educadores de Turismo das três Américas, destacou-se a consideração da "Formação Profissional como Fator-Chave do Êxito para Competição c Sucesso Empresarial” (Trigo, 1994:51).

Nesse evento repetiram-se as preocupações c recomendações feitas ao setor educativo do Turismo, relacionadas com a integração entre cmpresas c escola. Também foi destacada a necessidade da formação abranger um amplo espectro de capacitação nos níveis básico, médio c gerencial assim como a consideração das características regionais na constituição curricular dos cursos de Turismo e Hotelaria.

Constatou-sc, assim, que os problemas relacionados com a capacitação c a absorção dos profissionais pelo mercado de trabalho se assemellam à maioria dos países americanos c que os principais desafios na década de 9() basicamente continuarão a ser os seguintes:

- dificuldades na contratação de profíssionais diplomados, na medida em que hotéis c companhias aéreas formam parte do scu quadro

- visão dos graduados como ameaça aos trabalhadores sem título acadêmico que, contratados por um salário menor, constituem uma concorrência bastante forte;

- visão de alguns profissionais da formação superior como um aglomerado de teorias sociológicas supérfluas;

- falta de "status" do curso, que afasta alunos mais bem-dotados;

- evasão acentuada (superior a 5(\%) nas escolas, motivada, provavelmente, pelas dificuldades estruturais c sociais da profíssão;

- necessidade de se cstabelecer um quadro conceitual de compctência para professores c alunos, com reflexos na qualidade, c uma metodologia cuidadosamente planejada 
Para o futuro recomendou-se que os profissionais tenham uma visão clara do contexto no qual vão trabalhar, valorizando os conhecimentos necessários para um posicionamento competitivo no setor. As escolas, por sua vez, deverão adaptarse às novas configurações internacionais, especialmente na utilização de novas tecnologias, e ao fenômeno da globalização (Trigo, 1994).

Pelo exposto, conclui-se que as discussões sobre o tema ainda se estenderĩo por longo tempo, apesar de já haver um relativo consenso no que se refere à interdisciplinaridade dos conteúdos programáticos, à necessidade de estudos superiores (universitários) e do treinamento e da prática profissional.

Atualmente, os institutos superiores e técnicos de ensino do Turismo $\mathrm{cm}$ diversas partes do mundo apresentam estruturas curriculares diversificadas, tanto na extensão temporal do curso como na abordagem das disciplinas (quantitativa $\mathrm{c}$ qualitativa) e também na ênfase para os estudos gerenciais ou profissionalizantes, adequando-os - ou não - às cxigências do mercado de trabalho. Para o futuro, acredita-se que esse quadro dificilmente se unificará, devido, principalmente, à falta do reconhecimento da importância sociocconômica da atividade turistica e de seus efeitos nas comunidades receptoras.

Por isso, todas as medidas são, geralmentc, tomadas apressadamente c sob o impacto da necessidade de se proverem respostas rápidas para problemas imediatos, prejudicando as ações e investimentos a médio c longo prazos. Esse imediatismo resultará no fato deque, cm cinco ou dez anos, estarãosendo discutidos os mesmos problemas que hoje afligem os educadores, os pesquisadores $\mathrm{c}$ os profissionais da área.

Para mudar esse quadro até o século XXI, necessita-se de melhor qualificação dos recursos humanos, o uso apropriado das novas tecnologias c a ampliação dos serviços de informação da oferta turistica e das estatísticas sobre a demanda. Só então, poder-se-á ter mais certezas para um setor que se caracteriza pelas incertezas e imprevistos.

\section{Ensino em Turismo e Hotelaria no Brasil}

\section{Diagnóstico}

Os cursos e programas de cnsino cm Turismo no Brasil são oferecidos por diversas entidades. Existem na área vários tipos de cursos alinhados a diferentes objetivos de formação de recursos humanos. Alguns são regulamentados, outros não. Em termos gerais, o ensino em Turismo pode ser dividido $\mathrm{cm}$ superior (graduação e pós-graduação), técnico e livres.

Os cursos técnicos (alguns equivalentes ao $2^{\circ}$ grau c outros que cxigem o $2^{\circ}$ grau completo como pré-requisito) procuram a formação técnico-profissional dos seus alunos para que atuem na área. Destacam-se aqui os cursos Técnico de Turismo (equivalente ao $2^{\circ}$ grau) c Técnico de Guia de Turismo. Nesse último caso a profissão de Guia de Turismo está regulamentada, sendo que as instituições que oferecem tais cursos derem seguir a regulamentação e serem credenciadas pela Embratur.

Os cursos livres são dirigidos às necessidades de formação, treinamento. atualização c aperfeiçoamento de recursos humanos nárea (hotelaria. agência de atualizaça restaurantes. cmpresas de crentos etc.). Como não são autorizados por órgãos oficiais, tais cursos seguem normalmente um plancjamento anual (ou órgãos of cestral) c sua tipologia não ć padronizada. Variam cm função da modalidade/ tipo, duração e carga horária e scu enfoque reflete a grande variedade de profissões/ atividades cristentes náréa de Turismo e Hotelaria

Contatos com o MEC, Embratur. Senac, escolas superiores e de $2^{\circ}$ grau, além de outras entidades de cnsino cm Turismo c Hotelaria, evidenciaram uma realidade já esperada: falta de informações e estudos referentes à formação c capacitação de recursos humanos na área no Brasil. Em relação aos cursos técni

c livres. seu acesso limitou-se a folhctos de programação c informações orais quanto aos cursos de graduação c pós-graduação, cncontraram-sc algumas publicações c documentos, cuja síntesc compõe cste diagnóstico.

Em 1992, a Organização Mundial do Turismo publicou o I Repertório Mundial de Instilluciones de Eiluc:ación y Formación Turisticas, reunindo informações sobre mais de 6()() instituições. Essa publicação oferece um panorama de cursos de cducação c formação turísticas disponível cm todo o mundo, com dados confráveis sobre endereçamento. condições gerais para admissão, breve descrição doscursos oferecidos, meios de apoio ao ensino, idiomas utilizados e disponibilidade de ajuda financeira. Inclui 19 instituições brasilciras, sendo 15 de ensino superior, 2 de ensino técnico c cursos liveres e 2 de cnsino superior, técnico e cursos livres. Esse número de entidades de ensino brasileiras, embora significativo, não corresponde ao universo das mesmas. Além de ter sido editado cm 1992, muitas cntidades não responderam o questionário ou foram descartadas pelas respostas não estarem dentro dos padrões cstabelecidos

Com referência aos cursos técnicos (não equivalentes ao 2" grau) c cursos livres, os oferecidos pelo Serviço Nacional do Comércio - Senac, dão uma idéia da realidade desua ocorrência no Brasil. Em 1992, essa instituição ofereceu 12() cursos de Turismo cm todo país, sem contar os cursos de Hotelaria, área com maior tradição de atuação (Scnac, 1992). No ano seguinte, de um total de 1.372.26.3 alunos matriculados, $68.5(1)+(5 \%)$ foram na área de Hotclaria e $12.063(0,9 \%)$ na área de Turismo (Senac, 1994).

Os cursos dessa instituição são separados, por natureza de cnsino, nas Seguintes modalidades: "iniciação c aprendizagem, qualificação, habilitação, aperfeiçoamento, instrumentação c outros" (Senac, 1992).

Dados do Ministério da Educação e do Desporto referentes aos cursos superiores apontam a existência de 29 cursos de Bacharelado em Turismo c 6 de Tecnologia em Hotelaria no Brasil, cm 1994(MEC, 1994). A maioria dessescursos de graduação ( 16 de Turismo e de Hotelaria) concentra-se na região Sudeste, scndo que $80 \%$ dos cursos de Turismo e $68 \%$ dos cursos de Hotelaria pertencem e ltidades particulares de ensino. 
Nessa publicação aparece ainda um único curso de pós-graduação na área. o Mestrado cm Turismo c Lazer, oferecido pela Escola de Comunicações c Artes da Universidade de São Paulo. Não são mencionados dados referentes a out ros cursos na categoria de pós-graduação cm nível de cspecialização (MEC. 1994)

Outra publicação do MEC, o (enso Educacional 94, traz dados estatísticos sobre matrículas c concluintes dos cursos de graduação no Brasil. Tratando especificamente das matriculas cm Turismo c Hotclaria, estas represcntaram cn $1994,0,+\%$ do total de matrículas nos cursos de graduação no país (Secretaria de Educação Superior, 1994).

Em relação às matrículas de Turismo, de um total de 5876 , aproximadamente $48 \%$ foram realizadas nas universidades c $52 \%$ cm estabelecimentos isolados, federações de cscolas c faculdades integradas. Em ambos os casos, os maiores índices de matrículas permaneceram nas instituições particulares (cerca de $77 \%)$.

Situação similar ocorre com as matrículas cm Hotclaria. De um total de 1.()13 matrículas cm 1994, aproximadamente 39\% foram realizadas nas universidades c $61 \%$ nas outras instituições. Aqui também a maioria das matrículas foi fcita cm instituições particulares (cerca de 77\%).

Analisando as matrículas cm Turismo segundo as regiões brasilciras. : região Sudeste agrega aproximadamente $50 \%$ do total. Em seguida vem a região Sul, com aproximadamente $20 \%$, a região Nordeste com $19 \%$, a região Nortc com $7 \%$ c a região Centro-Oeste com 4\%. Em relação à Hotelaria, tambćm a maioria das matrículas situa-se na região Sudeste, com aproximadamente $62 \%$, seguida da região Nordestc com 27\% c da região Sul com 11\%. As regiões Nortc c CentroOcste não apresentaram matriculas cm Hotclaria cm 1994, segundo a Secretaria de Educação Superior (1994).

No estudo sobre cursos superiores de Turismo e Hotelaria no Brasil. realizado cm meados de 1994, Ansarah \& Rcjowski (1994) constataram a c.istência de +1 cursos de graduação (32 de Turismo c 8 de Hotclaria) c 12 cursos de pósgraduação cm nível de especialização. A maioria destes cursos (58\%) concentravasc na cidade de São Paulo (SP), scndo que os $42 \%$ restantes distribuíam-sc por Nata $(\mathrm{RN})$, Salvador (BA). Barbacena (MG), Rio de Janciro (RJ) c Balnéírio de Camboriú (SC). Nesses cursos de pós-graduaçĩo. cnfocam-sc também o Turismo c Lazer sob o ponto de vista macro atć temas mais específicos. como gerência de cmpresas turísticas, administração hotelcira e de eventos. gestão de negócios cm alimentação. plancjamento c marketing c turismo ambicntal.

A partir desses dados. percebe-se que a capacitação dos recursos humanos para o Turismo c a Hotclaria no Brasil $\mathbf{c} \mathrm{cm}$ indicando uma acentuada cxpansio quantitativa, cm todos os níveis: básico, tćcnico, superior e de pós-graduação. con destaque para os cursos de graduação - Bacharclado, c de pós-graduação /ate se sen.su. Essa cvolução quantitativa ocorre sem critćrios definidos e sem plancjamento. levando a uma saturação quantitativa do mercado de trabalho no setor, dificultando a contratação dos formados c reduzindo as oportunidades salariais para os graduados cm nivel supcrior.
Já os cursos técnicos atendem cm parte à demanda de senviços específicos que o sctor requer e scus cmpresírios recorrem ao trcinamento (formal c informal) na própria cmpresa para suprir scus quadros operacionais. O treinamento informal scnão for bem-oricntado c plancjado pode causar mais problemas do que soluções a médio prazo.

No que se refere aos aspectos qualitativos dos recursos humanos para o Turismo nota-se a mesma problemática do ensino cm todas as profissões, agravando-se pela carência de docentes capacitados para o magistério nas disciplinas cspecíficas do setor

Em todos os níveis, não há referencial institucional amplo para as estruturas curriculares que se baseiam em seis disciplinas para os Cursos Superiores cm Turismo (Parecer 35/71 do cxtinto Consclho Estadual de Educação), c na regulamentação da profissão de Guia de Turismo. Alćm disso, cada instituição de cnsino determina sua estrutura curricular, bascada cm modelos nacionais ou internacionais, pouco se alinhando às caracteristicas regionais ou ao contexto da atividade no país, no que se refere às cxigências $\mathrm{c}$ às necessidades do mercado de trabalho.

\section{Cursos Regulares versus Cursos Não-Regulares}

Os cursos regulares c não-regulares foram analisados $\mathrm{cm}$ cinco cidades brasilciras: Manaus, Salvador, Rio de Janciro, São Paulo c Florianópolis. com base cm um cadastro de entidades de formação c capacitação de recursos humanos cm Turismo c Hotclaria no Brasil, e nos seguintes tipos de entidades: cscolas de cnsino supcrior. cscolas de $2^{\circ}$ grau, cntidades institucionais de capacitação. associação c entidades de classe, órgãos oficiais, institutos, cmpresas públicas c autarquias c cmpresas privadas.

A partir de contatos telefônicos, entrevistas não-cstruturadas c correspondências, levantaram-se 103 entidades de ensino na área como mostra a Tabela 1 .

TABELA 1-CURSOSREGULARESENÃO-REGULARESEMTURISMOEHOTELARIA NO BRASIL POR CIDADE - 1995

\begin{tabular}{l|c|c|c}
\hline Cidades & $\begin{array}{c}\text { Cursos Regulares } \\
\left(\mathbf{n}^{\circ}\right)\end{array}$ & $\begin{array}{c}\text { Cursos Não-Regulares } \\
\left(\mathbf{n}^{\mathbf{0}}\right)\end{array}$ & $\begin{array}{c}\text { Total } \\
\left(\mathbf{n}^{\mathbf{0}}\right)\end{array}$ \\
\hline Sảo Paulo & 12 & 22 & 34 \\
Rio de Janeiro & 7 & 19 & 26 \\
Salvador & 5 & 10 & 15 \\
Florianópolis & 3 & 10 & 13 \\
Manaus & 3 & 12 & 14 \\
\hline Total & 30 & 73 & 103 \\
\hline
\end{tabular}


Quanto à modalidade de cursos oferecidos optou-se pela caracterizaçĩo apresentada na Tabela 2.

TABELA 2 - TIPOS EMODALIDADESDE CURSOS DE TURISMO E HOTELARIA NO BRASIL - 1995

\begin{tabular}{l|l}
\hline Tipo de Curso & Modalidade \\
\hline Regular & Pós-graduação "scrito sensu" - Mestrado/ Doutorado \\
& Pós- graduação "lato sensu"- Especialização/Aperfeiçoamento" \\
& Graduação \\
& $2^{\circ}$ grau técnico profissionalizante \\
& Outros \\
Não- Regular & Formação inicial/Treinamento para aquisição de habilidade \\
& Atualização/Reciclagem de conhecimentos \\
& Desenvolvimento/Aperfeiçoamento \\
& Treinamento comportamental(liderança, relações humanas etc.) \\
& Outros \\
\hline
\end{tabular}

(*) Embora tais cursos não sejam regulares sob a otica do Governo Brasileiro, para fins desta análise foram assim considerados pelas caracteristicas similares às outras modalidades de cursos regulares.

A partir dessa distribuição, enviaram-se os questionários às entidades. obtendo-se o retorno de aproximadamente $54 \%$, o que constitui uma amostra de 55 entidades. Os resultados obtidos são descritos a seguir.

\section{Escolas e Entidades com Cursos Regulares}

Das entidades avaliadas, $58,8 \%$ ofereciam cursos de pós-graduação, $58.8 \%$ cursos de graduação e $47,1 \%$ cursos de $2^{\circ}$ grau, respectivamente (respostas múltiplas - Tabela 3).

TABELA 3 - PROFESSORES POR CURSO DE TURISMO E HOTELARIA NO BRASIL - 1995

\begin{tabular}{l|c}
\hline \multicolumn{1}{c|}{ Curso } & Professores ( $\mathbf{n}^{\circ}$ médio) \\
\hline Pós-graduação (mestrado/doutorado) & 5 \\
Pós-graduação (especialização) & 9 \\
Graduação & 26 \\
$2^{\circ}$ Grau Técnico/Profissionalizante & 23 \\
\hline
\end{tabular}

A maior concentração de professores nas escolas entrevistadas ocorreu na graduação (26). Nos cursos técnico/profissionalizantes o número médio de 23 professores não se refere especificamente aos professores da área de Turismo, mas sim todos os professores desses cursos que ministram várias matérias de $2^{\circ}$ grau (português, matemática etc.). No que se refere aos cursos de pós-graduação de (porto somente a Universidade de São Paulo oferece essa modalidade c apenas em nível de mestrado, o Mestrado cm Turismo c Lazer".

Dos cursos regulares, 55,6\% mantinham convênios com entidades nacionais ou internacionais, com a finalidade de promover intercâmbios de alunos c docentes. Dos convênios com entidades nacionais, $42,8 \%$ cram com associações/ entidades de classe, $26,6 \%$ com universidades e os convênios com o Senac/Sebrae correspondem a $14,3 \%$. Entre os convênios com entidades internacionais, foran citadas a Organização das Nações Unidas - ONU, a Organização Mundial do Trabalho - OMT, a Organização Internacional de Turismo - OIT ou bancos internacionais, como o Banco Interamericano de Desenvolvimento - BID.

Os cursos ministrados pelas escolas regulares, $17,6 \%$ destinaram-se à formação de pessoal para a área privada; $5,9 \%$ formavam recursos humanos apenas para o setor público c $76,5 \%$ dos entrevistados declararam formar recursos humanos tanto para o setor público como privado.

Em relação ao espaço físico, todas as escolas entrevistadas possuíam espaço próprio para salas de aula, com capacidade média de 41,7 alunos por sala. Embora a maioria das entidades (cerca de $70 \%$ ) tenha respondido que possuía biblioteca especializada e laboratório de informática, verilicou-se, através de contatos telefônicos, que, em ambos os casos, tais espaços atendiam alunos de outros cursos da escola, não somente os de Turismo/Hotelaria. Assim, há certamente acervo c programas de informática especializados, mas cm que quantidade e qualidade? Por outro lado, 70,6\% declararam que não possuíam espaço físico para o laboratório de Turismo; $64,7 \%$ para o laboratório de idiomas, c das entidades que responderam que possuiam uma sala, esta tem capacidade para 29,5 alunos.

A maioria das entidades pesquisadas não possuia agência de viagem experimental $(70,6 \%)$ tampouco hotel-escola ou restaurante pedagógico $(88,2 \%)$ enquanto $35,3 \%$ possuíam setor de pesquisas e $64,7 \%$ setor de estágio; c apenas $15 \%$ declararam manter empresa júnior.

A participação do setor empresarial ("irade") nas instituições ocorreu na maior parte delas $(70,6 \%)$ e deu-se através da oferta de empregos $(64,7 \%)$, da participação em scminários, palestras $(52,9 \%)$ c da proposta de novos cursos $(23,5 \%)$ (respostas múltiplas). A participação $\mathrm{cm}$ conselhos/comissões foi de $17,6 \%$, assim como a recomendação de conteúdo programático dos cursos. Em $5,9 \%$ dos cursos regulares, o "trade" participou com doações e $29,4 \%$ dos mesmos declararam possuir um plano de cargos e de salários para o seu corpo docente.

Quanto à avaliação dos cursos, $82,4 \%$ dos entrevistados declararam realizíla periodicamente, através da avaliação das notas dos alunos, pesquisa com c.alunos e estudantes atuais. Nota-se, aqui, a avaliação unilateral, centrada apenas no aluno, sem inserção do docente e do "trade". Das escolas que não realizam 
avaliações (17,6\%). os motivos alegados foram a falta de pessoal c de recursos A avaliação do desempenho dos docentes foi feita através da opinião dos alunos $(70,6 \%)$. pela participação cm cursos c outros crentos científicos $(35,3 \%) \mathrm{c}$ pelo progresso na carreira ( $11,8 \%$ ) (respostas múltiplas). O motivo alegado pelas escolas que não avaliam os seus docentes relacionou-se com a falta de pessoalirecursios

Os respondentes julgaram a absorção de seus alunos no mercado de trabal ho como "bom" (53\%), como "regular" (23,5\%), como "ruim" (11,7\%) c apenas $5,9 \%$ como "ótimo". Os que responderam que a absorção de seus formados pelo mercado de trabalho é "num" justificaram sua resposta com evasivas c os que citaram os motivos referiram-se à falta de visão e informações do empresariado quanto à necessidade de recursos humanos qualificados.

TABELA 4-REALIDADEATUAL EPERSPECTIVAS DOS SEGMENTOS QUE MAIS ABSORVEM RECURSOS HUMANOS - CURSOS REGULARES (RESPOSTAS MÚLTIPLAS)

\begin{tabular}{l|c|c}
\hline Segmentos & $\begin{array}{l}\text { Necessidade de } \\
\text { Recursos Humanos - } \\
\text { próximos três anos } \\
(\%)\end{array}$ & $\begin{array}{l}\text { Segmentos que mais } \\
\text { Absorvem os Alunos } \\
\text { dasEscolas (atualmente) } \\
(\%)\end{array}$ \\
\hline Hotelaria & 100,0 & 60,3 \\
Agências de Viagem & 76,2 & 100,0 \\
Eventos/C. de Convençỏes & 59,5 & 20,7 \\
Transporte Aéreo & 23,8 & 13,8 \\
Guia Turistico & 11,9 & 22,4 \\
Restaurantes e Similares & 11,9 & 20,7 \\
Ensino & 0,7 & 0,3 \\
Consultoria & 35,7 & 12,0 \\
\hline
\end{tabular}

Na comparação dos dados, destaca-se que as cxpectativas dos entrevistados. para os próximos três anos, em relação ao mercado de trabalho para os formados cm escolas em cursos regulares, apresentaram-se bastante diversificada. A diferença entre o que se espera c a realidade demonstrou uma cxpectativa otimista para 0 setor de eventos no que se refere à absorção dos formados pelos cursos regulares. assim como a área de consultoria, a de ensino, as de empresas de transportes aéreos $\mathrm{c}$ as de hotelaria. Os entrevistados acreditam que empregos como guia de turismo e nas agências de viagem sofrerão declínio, embora este último se destacou como o primeiro mercado de trabalho dos egressos dos cursos atualmente (Tabela 4 ).

Dos entrevistados, $52,9 \%$ julgaram o apoio dos órgãos públicos e privados a formação de recursos humanos como "bom": 29.4\%"regular"; 5,9 \% "péssimo" c $5,9 \%$ não souberam avaliar.

$\mathrm{Na}$ opinião dos entrevistados, as seguintes medidas deveriam ser tomadas para aprimorar a formação c treinamento dos recursos humanos na área (respostas múltiplas):

- preparar mellior os docentes (100\%);

- aumentar a oferta de cursos para formação ou treinamento específicos $(87,5 \%)$;

- mellıorar/adequar os cursos cxistentes $(50 \%)$ :

- ampliar a assistência cmpresarial (50\%);

- estimular a realização de estudos e pesquisas científicas (45\%);

- dar apoio a estágios, bolsas de estudos e treinamento dos alunos $(37,5 \%)$

- apoiar a realização de cursos/programas nas cmpresas de Turismo/Hotelaria $(20 \%)$;

- aumentar a oferta de cursos gratuitos $(8,25 \%)$;

- aumentar a oferta de cursos de formação geral (4\%)

No que se refere à compatibilidade dos cursos com as necessidades do mercado de trabalho, $47,1 \%$ dos entrevistados julgaram seus programas adequados, enquanto $52,9 \%$ discordaram dessa afirmação. Os motivos alegados relacionaram-se, principalmente, com o sistema de ensino da escola e citam, especificamente, a inadequação do currículo $(55,5 \%)$, a falta de professores com qualificação teórica e didática $(22,2 \%)$, a falta de professores com cxperiência prática $(22,2 \%)$ e o não cumprimento pleno do currículo (11.1\%).

\section{Escolas e Entidades com Cursos Nāo-Regulares}

A maioria das escolas entrevistadas e que ministram cursos livres pertence a associações e entidades de classe

A maioria das escolas de cursos livres entrevistadas $(70 \%)$ mantinham convênios, sendo $50 \%$ com entidades nacionais, $1+, 3 \%$ com internacionais c $35.7 \%$ com ambas. As finalidades desses convênios relacionaram-se com o intercâmbio de 
publicações, realização de estudos c pesquisas conjuntas, oferta de cstagios. utilização de dependências para cursos e treinamento de pessoal. Através de contatos telefônicos, verificou-se que é rara a realização de estudos e pesquisas conjuntas, cmbora esse item figure cm convênios.

Dos convênios com entidades nacionais, $23,8 \%$ foram com associações de classe; $23,8 \%$ com universidades/escolas, $19 \%$ com o Senac, $19 \%$ com o Scbrac o $14,4 \%$ com órgãos oficiais. Os convênios internacionais foram firmados entre Ceseth - SC c o Cincap (Argentina), o Instituto Capacitação Turistica (Uruguai) c o Instituto Interamericano de Turismo (Estados Unidos). Citoul-se, ainda, o convênio com o Banco Interamericano de Desenvolvimento - BID.

Os cursos livres ministrados pelas escolas entrevistadas destinaram-se basicamente, à formação de pessoal para a área privada $(57,9 \%)$, sendo que os $42,1 \%$ restantes formaram recursos humanos tanto para o setor público como privado. Portanto, tais entidades voltaram-se preferencialmente à formação e capacitação de recursos humanos para a área privada.

Em relação ao espaço físico, a maioria das cscolas entrevistadas $(68,7 \%)$ possui espaço próprio para as salas de aula, com capacidade média de 35 alunos por sala: $64.7 \%$ não possuíam espaço físico para biblioteca especializada; $23.5 \%$ declararam possuir espaço físico para laboratório de Turismo; $77,8 \%$ não possuian espaço físico para laboratório de idiomas c $22,2 \%$ possuíam uma sala, con capacidade para 32,5 alunos. Apenas $17,6 \%$ possuíam o espaço físico para 0 laboratório de informática, sem declarar o número de salas e sua capacidade.

Dos entrevistados apenas $15,7 \%$ possuíam agencia de viagem experimental $11,7 \%$ hotel-cscola; $33,3 \%$ restaurante pedagógico, sem declarar seu espaço físico c capacidade; $31,2 \%$ setor de pesquisas $29,4 \%$ setor de estágio e $16,6 \%$ empresa júnior.

A participação do setor empresarial ("trade") nas instituições ocorre cı mais da metade $(64,7 \%)$, e se deu através da participação $\mathrm{cm}$ seminários, palestras $(63,6 \%)$, da oferta decmpregos/cstágios $(81,8 \%)$, cm conselhos/comissões $(45,4 \%)$ c da proposta de novos cursos/programas $(72,7 \%) .{ }^{5}$ Ressaltou-se , porém, que o "trade" participou pouco da concessão de bolsas de estudos (9\%) c da avaliação do contcuido programático dos cursos (18\%). O sctor também não contribuiu com doações $\mathrm{cm}$ nenhum caso pesquisado.

A maioria dos formados $(65,6 \%)$ atuaram na área de Turismo/Hotelaria: $9,4 \%$ não atuaram na área c 18,1\% estavam desempregados; e cm alguns casos $(6,9 \%)$ não foi possível avaliar esse item. Mais da metade dos respondentes $(64,6 \%)$ julgaram a absorção de seus alunos no mercado de trabalho como "bom" c $(35,3 \%)$ como "regular".
TABELA 5-REALIDADE ATUAL EPERSPECTIVAS DOS SEGMENTOS QUE MAIS ABSORVEM OS RECURSOS HUMANOS - CURSOS LIVRES

\begin{tabular}{l|c|c}
\hline segmentos & $\begin{array}{c}\text { Necessidade de } \\
\text { Recursos Humanos - } \\
\text { próximos três anos } \\
(\%)\end{array}$ & $\begin{array}{c}\text { Segmentos que mais } \\
\text { Absorvem os Alunos } \\
\text { dasEscolas (atualmente) } \\
(\%)\end{array}$ \\
\hline Hotelaria & 32,4 & 39,2 \\
Restaurantes e Similares & 16,8 & 6,3 \\
Agências de Viagem & 13, & 2,8 \\
Eventos/C de Convençỏes & 12,0 & 5,4 \\
Ensino & 8,3 & - \\
Guia Turistico & 3,7 & 8,7 \\
Órgãos Oficiais & 2,8 & - \\
Consultorias & 2,8 & 2,2 \\
Transporte Aéreo & 1,8 & - \\
Transporte Rodoviário & 1,8 & - \\
Transporte Maritimo & 0,9 & - \\
Outros & 3,7 & - \\
\hline
\end{tabular}

Na comparação dos dados (Tabcla 5), notou-se que, na área da hotelaria, as perspectivas $\mathrm{c}$ a realidade atual, embora decrescente, mantiveram a primazia na absorção de mão-de-obra $(32,4 \%)$. Houve uma cxpectativa favorável cm relação à realidade do mercado de trabalho para o setor de restaurantes e similares e no de cventos/centros de convenções. As agências de viagem cmpregaram mais alunos do que as cscolas julgaram $\mathrm{c}$ do que cmpregarão nos próximos três anos, o mesmo aconteceu com os guias de turismo c com o transporte aćreo. Os respondentes acreditaram que nos próximos três anos a área de ensino absorverá parte dos formados (18,3\%), fato que não acontecia cm 1995

A cxpectativa em relação ao apoio dos órgãos oficiais à formação de recursos humanos foi julgada como "regular" (37.5\%): "bom" (31.2\%) c "ótimo" (12.5\%).

$\mathrm{Na}$ opinião dos entrevistados. as seguintes medidas deveriam ser tomadas para aprimorar a formação c treinamento dos recursos humanos na área:

- aumentar a oferta de cursos com formaçĩo/trcinamento especifico (29.6\%):

- preparar melhor os docentes (15.7\%);

- dar apoio a bolsas. cstágios e treinamentos dos alunos (13\%):

- maior assistência cmpresarial (10.2\%) 
- estimular a realização de estudos e pesquisas de caráter cientifico (10.2\%):

- apoiar a realização de cursos/programas dentro das próprias empresas de Turismo c Hotclaria $(8,3 \%)$;

- aumentar a oferta de cursos gratuitos $(5,6 \%)$ :

- melhorar/adequar os cursos cxistentes $(4,6 \%)$ :

- aumentar a oferta de cursos de formação geral $(1,9 \%)$

- outros $(0,9 \%)$

No que se refere à compatibilidade dos cursos com as necessidades do mercado de trabalho, 61,1\% responderam afirmativamente a questão c $38.9 \%$ negativamentc. Os motivos alcgados relacionaram-se com:

- o sistema de cnsino da escola (40\%):

- as instalações c logística da cscola $(40 \%)$;

- os problemas relacionados com o aluno $(20 \%)$

Dos respondentes que alegaram problemas com o sistema de ensino do país todos se queivaram da "falta de cxperiencia prática" dos docentes c da falta de professores qualificados. A falta de laboratório foi apontada como o maior problema das instituições de ensino; c dos problemas relacionados com os alunos, destacouse a freqüente declaração de que estes apenas se interessam pela prática

\section{Consideraçōes Finais}

Da análise da adequação da capacitação dos recursos humanos com : realidade do mercado de trabalho nas empresas turisticas, conclui-se que:

- tanto os cursos regulares como os livres formam profissionais para os setores público c privado de Turismo, destacando-sc. cntretanto. a maior incidência de graduados atuando $\mathrm{cm}$ cmpresas privadas:

- o sctor privado participa ativamente em mais da metade das instituições pesquisadas, proferindo palestras c atuando $\mathrm{cm}$ seminários e consclhos. alćm de oferecer cstágios e empregos aos alunos:

- em relação ao corpo docente. cerca da metade dos cursos regulares possuem um plano de carreira para seus professores, cujo desempenho é avaliado através de sua produção cientifica c dos niveis de aprovação/reprovação de alunos

- con reláção à absorção dos formados nos cursos pesquisados pelo mercado de trabalho de Turismo, destacam-se as áreas da hotelaria, agências de viagem (inclusive guias de turismo) c os restaurantes e similares. As empresas que menos participam no recnutamento dos egressos desses cursos são as de ev'entos c as de transporte aéreo. Comoáreas cmergentes para os próximos três anos, os entrevisados apontaram o ensino c a consultoria;

- a maioria das instituições entrevistadas, tanto as que oferecem cursos regulares $(53 \%)$ como as de cursos livres $(64,7 \%)$, julga a absorção dos seus egressos pelo mercado de trabalho de Turismo como "boa" c a minoria como "ótima", o que demonstra que o aproveitamento não se apresenta sintonizado com o número de formados que as cscolas preparam para os seniços turísticos:

- os problemas citados pelos cntrevistados para esta situação são a incompatibilidade dos cursos com as necessidades do mercado de trabalho, motivada pelo sistema de ensino falho, tanto nas escolas regulares como nas livres, nas quais faltam laboratórios; as estnituras curriculares inadequadas às cxigências do mercado; c os docentes que não têm a necessária qualificação teórica c prática.

Com base nesses resultados sobre a formação c capacitação de recursos humanos para a área de Turismo/Hotelaria nas cidades pesquisadas, formulam-se as seguintes recomendações:

- conscientizar as autoridades, o "trade" c as cntidades sobre o papel c a importância da formação e capacitação de recursos humanos em todos níveis, a necessidade de uma formação continuada visando o aprimoramento, a eficiência, a competitividade e a melhoria da qualidade cm Turismo.

- controlar a abertura de novos cursos regulares superiores, diante das reais necessidades de recursos humanos na região, estabelecendo condições mínimas de qualidade para o seu funcionamento: contcúdo curricular, instalações adequadas, laboratórios equipados, bibliotecas especializadas, corpo docente capacitado etc

- fomentar a criação de cursos técnicos regulares, equivalentes ao $2^{\circ}$ grau, preferencialmente nos municipios com potencial turistico, de modo a preparar a mão-de-obra em um nível de qualificação requerido pelo mercado. Esta proposta, para ser bem-sucedida, não deve prescindir da participação do "trade" c da comunidade para a consecução de seus objetivos, atć porque a interação teóricoprática só se viabilizará pela integração cmpresa-cscola; 
- fomentar a oferta de cursos lives. nas modalidades requeridas e adequadas i realidade do mercado. dirigidos tanto a entidades públicas quanto a privadas. cm seus diferentes conteudos e níveis.

da mão-de-obra menos qualificada. em seus aspectos de higienc. postura pessoal expressão ...

- criar mecanismos que favoreçam o desenvolvimento de cursos do "tipo Sénac:" cm localidades turísticas não contempladas devidamente, especialmente nas regiões Nortc. Nordeste c Centro-Oestc, nas quais o Turismo se constitui em umi de suas mais importantes atividades cconômicas:

- estimular a melhor preparação dos docentes que atuam na área. crigindo maior investimento por parte das entidades formadoras dos mesmos: sensibilizal as agências de financiamento sobre a importância do Turismo Brasilciro e a necessidade de mais oferta de bolsas de estudo para pescenisas: propor • desenvolvimento de cursos-piloto em diferentes niveis. dirigidos aos docentes em regiões prioritárias do país, promovidos por entidades oficiais ou de classes e outras instituições:

- mostrar que a avaliação dos cursos; alunos e docentes deve ser realizaldi periodicamente e segundo uma metodologia adequada, a fim de que a mesma contribua para uma melhor orientação dos cursos as reais necessidades di formação/capacitação de recursos humanos na área.

Em suma, para os próximos anos, será indispensárcl uma melhor qualificação de recursos humanos que possa aumentar o poder de competitividade das cmpresas turisticas no mercado nacional c internacional. E, mais, as decisões serĩo tomadas, cada vez mais, com base nos resultados de estudos e pesquisas e segundo diretrizes traçadas por um plancjamento.

Se cstas propostas, a cxemplo de outras já formuladas, sobre a necessidade de valorizar a formac:ão e capacitação de recursos humanos ne setor de Tirrisme não forem devidamente consideradas, num futuro próximo esta questão ainda scri objeto da necessidade de novos estudos c. mais uma vez, será postergarda a consecução dos objetivos desta pesquisa.

\section{Bibliografia}

ACERENZA, Miguel Angel. 1991. El Turismo su dinámica latinoamericana y sus limutaciones en el aréa de recursos

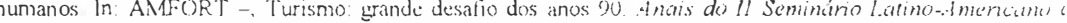

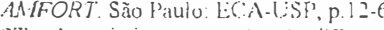

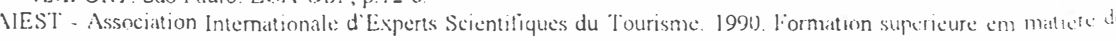
tourisme. Sa necessitt. Ses exigences $40^{\circ}$ Congres Rapports. St Gaillen. AIEST. 1.31

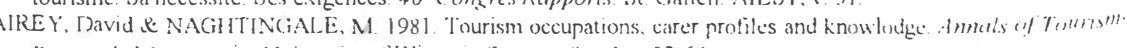

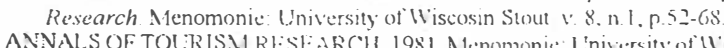

Tourism Education
ANSARAH, Marilia Gomes dos Reis \&. RI:JOll'SK'1, Mirian, 1994. Cursos superiores de turismo e hotelaria no Brasi

ANTON, David 1981. TOurim trainning in developing courves The sociat

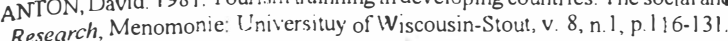

Researinistério do Traba

BRAPACITACIÓN turistica. Su aporte a los sectores público y privado. 1989. Buenos Aires: Amfort/CIET. 264 p

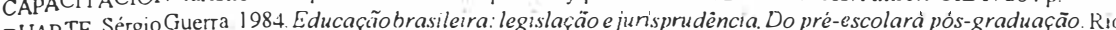
DUR Janeiro: Antares, 259 p.

de JaTUR - Instituto Brasileiro de Turismo. 1994a Cursos de turismo/nivel de $2^{\circ}$ grau. Rio de Janeiro: Embratur. $2 \mathrm{p}$ (listagem)

(listagem). Instituto Brasileiro de Turismo. 1994b. Escolas de Hotelaria no Brasil. Rio de Janeiro: Embratur. $8 \mathrm{p}$.
EMBRATUR (listagem)

EMBRATUR - Instituto Brasileiro de Turismo. 1994c. Curso de Guias. Rio de Janeiro: Embratur. 5p. (listagem)

EMBRATUR - Instituto Brasileiro de Turismo. 1994d. Faculdades de Turismo no Brasil. Rio de Janeiro: Embratur. $5 p$ (listagem).

$88 \mathrm{p}$.
JAFAR, Jafari. 1981. Special Issue. Tourism Education. Annals of Tourism Research. Menomonie: University of KASPAR, Claude 1980

1980. Introduction au théme general du congrés. In: AIEST Association Internationale d'Experts Scientifiques du Tourisme. 1990. Formation superieure en matiére de tourisme $40^{\circ}$ Congrés Rapports. St. Gallen: AIEST, v. 31

LEIPER, Nel. 1981. Towards a cohesive curriculum in tourism. The case for a distinct discipline Annals of Tourism Research, Menominie: University of Wiscousin-Stout, v.8, n

IEC-Ministério da Educą̧ão e do Desporto. 1994. Censo educacional 1994. Sinopse estatistica da educ açãosuperion Graduação. Brasilia. MEC/SAG/CPS/SEEC:, 219p.

PUDDU, Loi Giuseppe. 1991. In: AMFORT, 1991 Turismo: grande desafio dos anos 90. Anais do /l Seminário Latino Americano da AMFFORT. São Paulo: ECA.USP, p.62-75.

REGULAMENTAÇÃO de guia de Turismo.

REJOWSKI, Mirian, 1993. Fesquisa Académica em Turismono Brasil. Sistematizaçãoe configuração documental. São Paulo: ECA-USP, 2v. Tese de Doutorado.

. In: AIEST - Association Intermationale d'Experts Scientifiques du Tourisme. 1990. Formation superieure en matiér

ensino superior. Brasilia. SENAC - Servico Naciono Superior. 579p

turismo. Rio de Janeiro: SENAC-DN, 190 p. JAC - Serviço Nacional de Aprendizagem C'o

Janeiro: SENAC-DN, 36 P

TURISMO grande desafio dos anos 90. 1991. São Paulo: Amfor/ECA-USP. 193p

P. Luiz Gonzaga Grodoi. 1994. Congresso panamericano de escolas de hotelaria e turismo. Turismo em Análise São Paulo: ECA-USP

WTO - World Tourism Organization. 1992. World directory of tourism education and trainning institutions. Madrid: WTO. p. 103-121. a formação básic 